\title{
CULTURA DE APICES CAULINARES DE Musa sp, var. MAÇÃ: ESTABELECIMENTO, MICROPROPAGAÇÃO E ENRAIZAMENTO in vitro.
}

\author{
R.T. DOMINGUES1; A. TULMANN NETO² ; B.M.J. MENDES2 \\ 1- Centro de Citricultura Sylvio Moreira - LAC, C.P. 04 - CEP: 13.490-970 - Cordeirópolis, SP. \\ 2. Centro de Energıa Nuclear na Agricultura CENA/USP - C.P. 96 - CEP: 13.400-970 - Piracicaba, SP.
}

\begin{abstract}
RESUMO: Através de vários experimentos objetivou-se estudar as melhores respostas da variedade de banana "Maça" as técnicas de cultura de tecidos no que se refere ao tipo e dimensỉes dos explantes e ao melo de cultura para obtencão de uma malor taxa de multiplicaça in vitro. Os ápices caulinares utilizados como explantes foram obtidos em cinco diferentes maneiras. Observou-se que os d́pices caulinares com $0,7 \mathrm{~cm}$ de diâmetro basal por $1 \mathrm{~cm}$ de comprimento, dos quais foram retiradas as bainhas foliares, apresentaram malor número de brotos. $O$ meio liquido com agitaço fol o em que se observou um maior estímulo na brotaç̄o, superando o meio semi-sblido e o melo líquido sem agitacăo. A concentraçăo de BAP testada que permitiu a obtençâo de um maior número de brotos fol de $5.0 \mathrm{mg}$.-1. Para o enraizamento, a concentracilo de 0,1 mg.l-1 de ANA e AIB foi a mais adequada.
\end{abstract}

Descritores: bananeira, apices caulinares, micropropagacăo, enraizamento

\section{SHOOT TIP CULTURE OF Musa sp., var. MAÇÃ: ESTABLISHMENT, MICROPROPAGATION AND ROOTING}

\begin{abstract}
The response of banana shoot tips var: "Maça", were accessed for difierent micropropagation conditions such as media composition and explant type. Shoot tip apices were extracted in five different ways. Shoot tips without immature leaves with $0.7 \mathrm{~cm}$ in diameter and $1.0 \mathrm{~cm}$ in lenght, tended to produce a larger number of developing buds. The number of buds developed was higher in shoot tips grown in liquid media with agitation than in semi solid media. Shoot tips grown in static liquid media had the lowest number of bnds developed. The lowest concentration of the growth regulator BAP to produce a higher number of buds was $5.0 \mathrm{mg.l}-1$. For rooting, the best concentration of NAA and IBA was 0.1 mg.l-1. This concentration rooted plants in two weeks.
\end{abstract}

Key words: banana, shoot tip apices, micropropagation, rooting

\section{INTRODUÇÃO}

A bananeira é uma cultura de vital importância para milhres de pessoas no mundo todo, seja como fonte de alimentação direta ou como fonte de divisas. A produção mundial alcança aproximadamente 71 milhðes de toneladas por ano (FAO, 1991).

A micropropagação da bananeira pode contribuir para uma melhora da sanidade e uniformidade do material cultivado em campo, bem como para a propagação de clones que apresentem melhores características agronômicas (CRONAUER $e t$ al. 1984). Além disso tem se apresentado como uma ferramenta útil para o melhoramento genético desta cultura através de indução e exploração da variação somaclonal espontânea ou induzida através de mutagênicos químicos ou físicos (NOVAK et al. 1987)

$O$ presente trabalho foi realizado com a finalidade de se conhecer melhor as respostas da var.
"Maçă" às técnicas de cultura de tecidos, no que se refere ao melhor tipo de explante, meio de cultura e condiçøes mais adequadas para uma maior taxa de multiplicação in vitro.

\section{MATERIAL E METODOS}

Plantas jovens de banana" Maçã", com aproximadamente quatro meses, foram coletadas em campo, recebendo cortes no pseudocaule aproximadamente $20 \mathrm{~cm}$ acima do rizoma sendo lavadas em água, eliminando-se a terra $e$ as raízes. A seguir, as bainhas foliares que ainda restaram no pseudocaule, foram retiradas gradativamente, ao passo que 0 rizoma sofreu cortes sucessivos, até que o explante adquiriu $2,5 \mathrm{~cm}$ de diâmetro e $5 \mathrm{~cm}$ de comprimento, mantendo em seu interior o ápice meristemático intocado.

Estes explantes foram imersos em álcool $9^{\circ} \mathrm{GL}$ por 5 minutos, para a esterilização e quebra 
da tensão superficial, logo após foram transferidos para solução de hipoclorito de sódio (produto comercial $2,5 \%$ cloro ativo) diluido na proporção 1:3, por 20 minutos em agitador, para completar a esterilização superficial. A seguir foram enxaguados em câmara assteptica por 4 vezes com água destilada autoclavada.

Após este tratamento, com o auxílio de bisturi, foram deixados no explante apenas 3 ou 4 primórdios foliares recobrindo o meristema apical, ficando o explante com aproximadamente $2,0 \mathrm{~mm}$ de diâmetro. Nestas condições os explantes foram inoculados em meio de cultura $\mathrm{Ml}$, semı-sólido ou liquido, contendo sais minerais de MURASHIGE \& SKOOG (1962) (MS), macro e micronutrientes, v1taminas de MOREL \& WETMORE (1951) (MW), suplementado com $5,0 \mathrm{mg} .^{-1}$ de BAP, $3 \%$ sacarose, $\mathrm{pH} 5,7$ e 6,5 g. $\mathrm{H}^{-1}$ de ágar.

Os ápices caulinares foram incubados em sala de crescimento com temperatura controlada $\left(26^{\circ} \mathrm{C} \pm 2^{\circ} \mathrm{C}\right)$ e sob fotoperíodo de 16 horas de luz $\left(30 \mathrm{~W} / \mathrm{m}^{2}\right)$. As trocas de meio foram realizadas a cada 15 dias. Esta primeira etapa permitiu a multiplicação vegetativa do material, para utilização nas demais etapas deste trabalho. Parte destas plantas foram utilizadas para determinar a taxa de brotação de ápices caulinares extraidos de cinco diferentes maneiras, como ilustra a Figura 1:

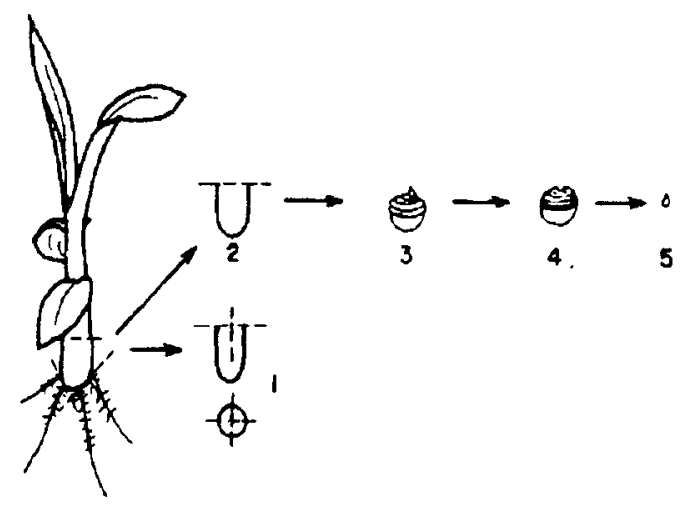

1.Ápice caulinar com $0,7 \mathrm{~cm}$ de diâmetro basal por $1 \mathrm{~cm}$ de comprimento, contendo o meristema apical mais gemas laterais sem a remoção das bainhas foliares e que sofreu dois cortes perpendiculares longitudinalmente até a altura do meristema. Estes cortes foram realizados para quebrar a dominância apical.

2.Ápice caulinar com $0,7 \mathrm{~cm}$ de diâmetro basal por $1 \mathrm{~cm}$ de comprimento, contendo o meristema apical mais gemas laterais sem a remoção das bainhas foliares.
3 Ápice caulinar com $0,7 \mathrm{~cm}$ de diâmetro basal por $1 \mathrm{~cm}$ de comprimento que sofreu remoção das bainhas foliares, contendo no entanto, o meristema apical mais as gemas laterass

4 Ápice caulınar com $0.7 \mathrm{~cm}$ de diâmetro basal por $1 \mathrm{~cm}$ de altura, contendo apenas as gemas laterais, uma vez que a que determınava a domınâncıa apical foi removida

5 Ápice caulinar com $0,1-0,2 \mathrm{~cm}$ de diâmetro, compreendendo a região merıstemátıca contendo 2-3 primórdios follares

Cada um dos tratamentos (tipos de explantes obtıdos em câmara de fluxo lâmınar) contou com 15 repetições. sendo cada parcela representada por um ápıce caulinar ınoculado indıvidualmente em Erlenmeyer de $250 \mathrm{ml} \mathrm{em} \mathrm{meio} \mathrm{de} \mathrm{cultura} \mathrm{M1}$ liquido e levados para sala de crescimento e mantidos sob agitação $(65 \mathrm{rpm})$ A avalıação foi realizada através da contagem do número de brotos após 30 dias

Com a finalidade de se comparar as respostas dos ápices caulinares quando inoculados $\mathrm{em}$ meio semi-sólido ou em meio líquido (com e sem agitação) para o estimulo das brotações em ápices caulinares de bananeira "Maçâ", utilizou-se 48 plantas estabelecidas in vitro, das quais foram extraidos os ápices caulinares com aproximadamente $0.7 \mathrm{~cm}$ de diâmetro basal por $1,0 \mathrm{~cm}$ de altura.

Foram inoculados em meio Ml semı-sólıdo, líquido com agitação e líquido sem agitação $O$ delineamento adotado foi o inteiramente casualizado, com 16 repetições, sendo cada parcela representada por um ápice caulinar inoculado individualmente em Erlenmeyer de $250 \mathrm{ml}$

Devido a controvérsias existentes na literatura especifica, sobre as melhores concentrações de BAP a serem utilizadas para a micropropagação da bananeira e devido haver respostas diferenciadas entre variedades distintas de Musa, como observado em BANERJEE \& DE LANGHE (1985), GUPTA (1986), GODINHO (1987), LAMEIRA (1987), foi realizado experimento para determinação das melhores concentrações de BAP para a indução de brotação em bananeira "Maçã". O experimento, em delineamento inteiramente casualizado, contou com 8 tratamentos $(0 ; 2,5 ; 5,0 ; 7,5 ; 10,0 ; 12,5 ; 15,0 \mathrm{e}$ $17,5{\mathrm{mg} . \mathrm{l}^{-1}}^{-1}$ e 16 repetições, sendo cada parcela representada por dois ápices caulinares.

Os explantes utilizados para este experimento foram obtidos a partir de 128 plantas cultivadas in vitro com aproximadamente $7,0 \mathrm{~cm}$ de altura 
e $0,7 \mathrm{~cm}$ de largura basal. Em câmara asséptica, foi realizado corte da parte aérea $1,0 \mathrm{~cm}$ acima do rizoma com o auxilio de pinça e bisturi flambados, retirando-se possiveis raizes.

Os explantes foram inoculados em meio de cultura $\mathrm{Ml}$, isento de fitoreguladores, com as diversas concentrações de BAP. Foram a seguir levados para sala de crescimento. O delineamento adotado foi o inteiramente casualizado e a avaliação foi realizada através do peso e do número de brotos emitidos após 45 dias.

Uma vez que existem autores que recomendam a utilização de reguladores de crescimento (auxinas) para a indução do enraizamento em Musa e outros que dispensam a sua utilização, realizou-se experimento para a determinação dos melhores reguladores de crescimento e concentrações adequadas a serem utilizados para o enraizamento de plântulas de bananeira "Maçã". Para tanto, foram usadas 130 plântulas, com aproximadamente $3,5 \mathrm{~cm}$ de altura, originadas do cultivo in vitro e que ainda não estavam enraizadas.

Os reguladores de crescimento testados foram as auxinas AIA, AIB e ANA, sendo que as plântulas foram inoculadas individualmente em tubos de ensaio contendo $25 \mathrm{ml}$ de meio $\mathrm{Ml}$, sem a presença de citocininas, com as auxinas citadas nas concentrações de $0 ; 0,1 ; 0,5 ; 1,0$ e 5,0 mg..$^{-1}$ e 1,5 g.t-1 de gel (phytagel-Sigma) e mantidas em sala de crescimento.

0 delineamento foi inteiramente casualizado com cinco tratamentos (doses) e 10 repetições (1 plântula por repetição). A avaliação foi feita através do número de raizes e comprimento do sistema radicular após 14 dias da inoculação.

Após as plântulas atingirem $6-9 \mathrm{~cm}$, foram levadas para casa de vegetação, onde foram aclimatadas em sacos plásticos de $10 \times 12 \mathrm{~cm}$, contendo mistura autoclavada de terra argilosa, maténa orgânica e areia nas proporções de 1:1:1, respectıvamente. As mudas foram colocadas dentro de câmara úmida durante 4 dias. Após este período, foram retiradas e mantidas dentro de casa de vegetação

As análises estatísticas foram realizadas através de análises de variância e foi utilizado o teste de Tukey para os dados de contagem transformados segundo $\sqrt{(x+1 / 2)}$ e através de equações de regressão, quando necessário.

TABELA 1. Número médio* de brotos obtidos através de cinco tipos diferentes de ápices caulinares de bananeira "Maçã" (Grupo $\mathrm{AAB}$ ) cultivados in vitro em meio líquido**

Tipos de ápices caulinares

Número médio de brotos

\begin{tabular}{lll}
\hline 1 & 1,93 & $\mathrm{~b}$ \\
2 & 1,67 & $\mathrm{~b}$ \\
3 & 3,96 & $\mathrm{a}$ \\
4 & 1,50 & $\mathrm{~b}$ \\
5 & 1,31 & $\mathrm{~b}$ \\
\hline
\end{tabular}

* As médias seguidas por letras distintas diferem entre si, pelo teste de Tukey, ao nivel de significância de 5\% - (CV. 14,09\%). ** A avaliação foi feita 30 dias após inoculação.

\section{RESULTADOS E DISCUSSĀO}

Os ápices caulinares inoculados, que a princípio possuíam a coloração creme, adquiriram a coloração verde após uma semana, CRONAUER \& KRIKORIAN (1984) também observaram estas alterações, porém, no presente trabalho, os explantes apresentaram leve escurescimento devido a oxidação superficial dos mesmos, a qual, não chegou a prejudicar o seu desenvolvimento.

Durante os primeiros vinte dias ocorreu entumescimento dos explantes, que cresceram diametralmente. Após 25-35 dias de cultivo iniciaram-se as brotações que atingiram em média 5-6 brotos por explante em $\mathbf{4 5}$ dias de cultivo.
Com relação à capacidade de brotação de ápices caulinares extraídos de diferentes maneiras, após um mês, os resultados podem ser vistos na TABELA 1. Em alguns casos, houve tendência para a formação de plântulas únicas, sem brotações laterais, isto ocorreu em alguns explantes pertencentes ao tipo 2. O tratamento que diferiu estatisticamente, apresentando o maior número médio de brotos foi o de número 3 , isto é, os ápices caulinares que sofreram a retirada das bainhas foliares e que continham o ápice caulinar apical mais as gemas laterais.

NOVAK et al. (1987) utilizaram explantes que correspondem ao tipo $5 \mathrm{com}$ a finalidade de indução de mutações. No presente trabalho, este explante apresentou tendência para menor média 
inicial de brotação ( 1,31 brotos em média), provavelmente devido a menor reserva nutricional contida e a maior possibilidade de estresse ambiental a que estão sujeitos devido ao seu pequeno tamanho. Porém este tipo de explante, quando originado diretamente de plantas do campo, minimiza a possibilidade de presença de vírus e outros patógenos segundo GUPTA (1986).

Para trabalhos de pesquisa que visem maior taxa de multiplicação in vitro, o presente trabalho sugere a utilização de ápices caulinares do tipo 3, porém, os ápices caulinares sem bainha foliares requerem maior trabalho para sua obtenção. Para fins de micropropagação pode-se recomendar também o tipo 1, que após o tipo 3, foi o que apresentou a tendência de uma maior produção de brotos e além disto exige menor trabalho para extração.

Vários autores, assim como MURASHIGE (1974) recomendam cuidado na escolha do estado físico do meio de cultura, uma vez que a taxa e o padrão de crescimento e morfogênese podem ser afetados A TABELA 2 apresenta as médias de brotos obtidos a partir do cultivo in vitro de ápices caulinares da var. Maçã em meio semi-sólido, líquido com agitação e líquido sem agitação durante 20 dias.

O meio líquido com agitação e o meio semisólido foram os tratamentos que apresentaram maiores médias (1,56 e 1,20 brotos, respectivamente) quando comparadas com o meio líquido sem agitação $(0,49$ brotos) Neste último caso a falta de aeração do meio líquido sem agitação deve ter provocado a redução na capacidade de brotação dos explantes, tal suposição concorda com MURASHIGE (1974) quando afirma que os explantes submergem quando em meio líquido estacionário prejudicando a troca gasosa.

O meio líquido apresentou média ligeiramente superior (não significativa) ao meio semi-sólido, tal tendência já havia sido observada por CRONAURER \& KRIKORIAN (1984), porém, o meio líquido possui o inconveniente de não permitir uma boa sustentação para os explantes. Este meio pode ser usado para o cultivo de ápices caulinares muito pequenos, os quais sofrem mais com a dessecação, $e$ inicialmente, não necessitam ser sustentados em posição fixa.

Deve-se evitar a utilização do meio líquido sem agitação, uma vez que, como sugerem os dados da TABELA 2 e de outros autores, como MURASHIGE (1974), a oxigenação é fator importante para uma boa taxa de brotação

Como não houve diferença significativa entre os meios semi-sólido e líquido para o cultivo de ápices caulinares, sugere-se a utilização dos semisólidos, devido a maior facilidade de manuseio, e dispensa da utilização de agitadores.

Com relação à influência das concentrações de BAP na brotação de ápices caulinares, os pesos médios e o número médio de brotos por tratamento aplicado, estão apresentados na TABELA 3. Nota-se que, em geral, na avaliação através de pesagens, a testemunha sem BAP apresentou o menor peso médio $(4,66 \mathrm{~g})$. Quando se avaliou através da contagem do número de brotos, a testemunha e o tratamento com $2,5 \mathrm{mg} / \mathrm{L}$ apresentaram as menores médias e a concentração de $5,0 \mathrm{mg} . \mathrm{l}^{-1}$ de BAP. o maior valor, que entretanto não diferiu estatisticamente das outras concentrações

Avaliando-se as médias dos números de brotos para as diferentes concentrações de BAP, observa-se que até $5,0 \mathrm{mg} /$, houve uma tendência para um aumento progressivo na formação de brotos nos ápices caulinares à medida que se elevou a concentração do regulador de crescimento (BAP), ocorrendo, posteriormente, uma tendência à queda e estabılidade. GODINHO (1991), apesar de trabalhar com plantas de bananeira in vivo, também observou que com a adição de BAP, ocorria uma elevação na indução de novos brotos até certo ponto $\left(10,0 \mathrm{mg} . \mathrm{L}^{1}\right)$. Estes dados correspondem ao observado no presente trabalho quando analisamos os dados de peso e número de brotos através das curvas de regressão, quan-

TABELA 2. Número médio de brotos obıdos por ápices caulinares de bananeira "Maçâa" cultivados in vitro em meio semi-sólido e liquido com e sem agitação ${ }^{* *}$

\begin{tabular}{cc}
\hline \hline Meio & Médias \\
\hline Semi-sólido & $1,20 \mathrm{a}$ \\
Liquido com agitação & $1,56 \mathrm{a}$ \\
Liquido sem agitação & $0,49 \mathrm{~b}$ \\
\hline \hline
\end{tabular}

\footnotetext{
Médias seguidas de letras iguais não diferem significativamente entre si pelo Teste de Tukey - 5\% (CV. $33,94 \%)$. A avaliação foi feita 20 dias após a inoculação.
} 
do a concentração de $10,0 \mathrm{mg} . \mathrm{I}^{-1}$ correspondeu ao ponto de máxima resposta, para as duas variáveis analisadas e, 5,0 mg.t-1 foi a menor concentração utilizada que produziu brotaçăo satisfatória (Figura 2).

GUPTA (1986) recomendou a utilização do BAP, nas concentrações de 0,7 a 5,0 mg..$^{-1}$, como citocinina indutora de brotaçes in vitro em Musa. Já LAMEIRA (1987) trabalhando com outras variedades de bananeira, recomendou a utilização da concentração de 2,5 mg.1-1 de BAP.

Para a var. Maçã a concentração de 2,5 mg.l-1 parece desaconselhável, pois produziu número relativamente baixo de brotos e não foi capaz de impedir o estímulo ao enraizamento, o qual uma vez iniciado reduz a formação de novos brotos. Já a concentração de $5,0 \mathrm{mg} . \mathrm{l}^{-1}$ parece ser a menor a permitir que os ápices caulinares respondam com maj- or intensidade ao estímulo da brotação, não havendo enraizamento para trocas de meio a cada 25 dias. Pelos resultados observados na TABELA 3 , o número crescente de brotos produzidos até a concentração de $5,0 \mathrm{mg} / \mathrm{L}$ permite recomendar a utilização de concentraçбes maiores do que 2,5 e menores do que $5,0 \mathrm{mg} / \mathrm{L}$ de BAP para a micropropagação da variedade Maçã. Esta faixa deve ser suficiente para uma brotação adequada, impedindo o enraizamento (indesejável nesta fase) e reduzindo os riscos da ocorrência de variação somaclonal que doses maiores poderiam acarretar. Não se conhece ao certo todos os fatores que induzem a variação somaclonal, provavelmente, em bananeira, os principais fatores sejam a instabilidade genética dos tecidos somáticos, a presença de gemas adventícias formadas nos tecidos do rizoma, independentemente da presença de calos, e a taxa de

TABELA 3. Peso e número médios" de brotos obtidos por parcela para bananeira "Maģa" (Grupo AAB) cultivados in vitro sob diversas concentraçסes de $\mathrm{BAP}^{* *}$

\begin{tabular}{|c|c|c|c|c|}
\hline \multirow{2}{*}{$\begin{array}{c}\begin{array}{c}\text { Concentração de BAP } \\
\left(\mathrm{mg} \cdot \mathrm{l}^{-1}\right)\end{array} \\
0\end{array}$} & \multicolumn{2}{|c|}{$\begin{array}{l}\text { Peso médio } \\
\text { (g) }\end{array}$} & \multicolumn{2}{|c|}{$\begin{array}{l}\text { Número médio } \\
\text { de brotos }\end{array}$} \\
\hline & 4,66 & b & 2,81 & c \\
\hline 2,5 & 11,47 & $\mathbf{a}$ & 8,25 & bc \\
\hline 5,0 & 16,51 & $\mathbf{a}$ & 16,84 & $\mathbf{a}$ \\
\hline 7,5 & 14,19 & $\mathbf{a}$ & 13,69 & $\mathbf{a b}$ \\
\hline 10,0 & 13,62 & $\mathbf{a}$ & 13,59 & $\mathbf{a b}$ \\
\hline 12,5 & 11,20 & $\mathbf{a b}$ & 12,19 & $\mathbf{a b}$ \\
\hline 15,0 & 12,71 & $\mathbf{a}$ & 11,70 & ab \\
\hline 17,5 & 10,88 & $\mathbf{a b}$ & 13,42 & $\mathbf{a b}$ \\
\hline
\end{tabular}

* Médias seguidas de letras iguais não diferem significativamente entre si pelo Teste de Tukey - 5\% (CV. $20,49 \%$ e $20,25 \%$ respectivamente). ** Avaliação 45 dias após inoculação.

TABELA 4. Comprimento médio ${ }^{*}$ de raizes (cm) em plântulas de bananeira "Maçã", cultivadas in vitro, através do uso de diversas concentrações de auxinas ${ }^{* *}$

\begin{tabular}{ccccc}
\hline $\begin{array}{c}\text { Concentracaio } \\
\text { (mg.1-1) }\end{array}$ & AIA & AIB & ANA \\
\hline 0 & 4,56 a A & 4,56 a A & 4,56 a A \\
0,1 & 1,95 b B & 4,12 a A & 3,38 ab A \\
0,5 & 2,30 b A & 1,70 b A & 2,00 bc A \\
1,0 & 0,73 c B & 1,26 bc AB & 1,76 c A \\
5,0 & 0,53 c A & 0,34 c A & 1,07 c A \\
\hline \hline
\end{tabular}

* Módias seguidas de letras iguais minúsculas ou maiúsculas, não diferem significativamente entre si, no sentido vertical e horizontal respectivamente. Avaliação pelo teste de Tukey - 5\% (CV.22,24\%).

** Avaliação após 14 dias da inoculação. 
repicagens in vitro e julga-se que os componentes do meio de cultura também influenciem neste processo, como os reguladores de crescimento em elevadas concentraçöes. SOUZA et al., (1994) observaram que plântulas de bananeira que passaram por sete subcultivos em meios contendo 7,5 e $10 \mathrm{mg} / \mathrm{L}$ de BAP apresentaram maiores frequências de células com adição de cromossomos e redução no número de células normais em relação a plântulas com menos tempo de cultivo ou em meios com menores concentraçס̄es de BAP. NOVAK (1991) atribui a três principais causas o aparecimento de variação somaclonal durante a micropropagação de Musa: alterações genéticas já existentes nos tecidos dos explantes, variações induzidas pela ação de mutagênicos do meio de cultura e variação devido ao estresse induzido pelas condições de cultivo. Portanto, até que existam evidências que comprovem que niveis elevados de BAP não contribuem para aumento da variação somaclonal na var. "Maçã", deve-se evitar altas concentrações.

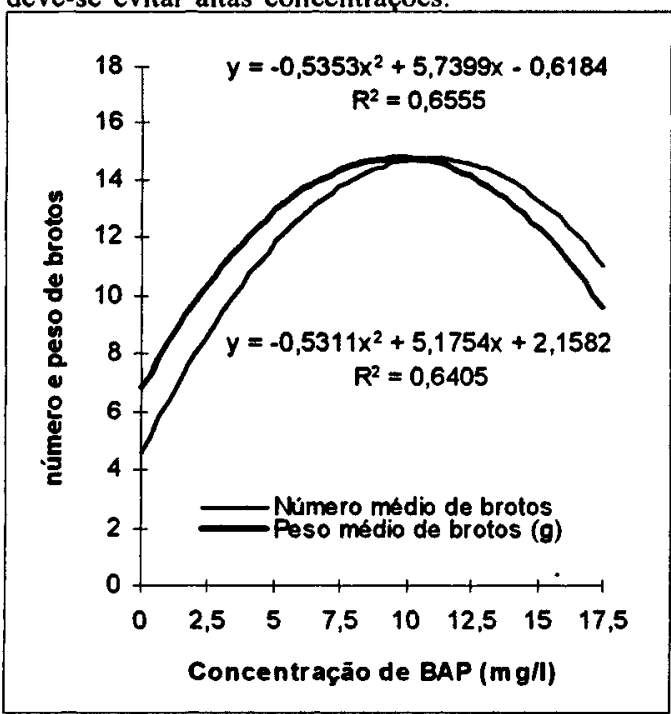

Figura 2. Número e peso de brotos observados em bananeira, var. Maçã, cultivada em meios de cultura contendo diversas concentrações de BAP.

Com relação às melhores concentrações de auxinas para o enraizamento, foram anotados o comprimento médio (TABELA 4) e o número médio das raizes (TABELA 5). Quanto ao comprimento das raízes, observou-se de modo geral que, com exceção do IBA e NAA para a menor concentração $(0,1 \mathrm{mg})$ L), à medida que aumentaram as concentrações, houve uma tendência à diminuiçăo do comprimento. Houve uma tendência a aumento no número médio de raízes com as menores concentrações $(0,1$ e 0,5 $\mathrm{mg} / \mathrm{L}$ ). Os dados referentes ao número de raizes também estão representados na Figura 3.

Levando-se em conta estes dois parâmetros, pode-se recomendar para esta variedade a concentração de $0,1 \mathrm{mgL}$ de NAA ou IBA para o enraizamento. LAMEIRA (1987) trabalhando com outras variedades de bananeira, sugeriu a utilização de $5 \mathrm{mg} / \mathrm{L}$ de IBA, o que, como se observou, não é necessário para a var. Maçã. De fato, as plantas originadas do tratamento com $0,1 \mathrm{mg} / \mathrm{L}$ foram capazes de produzir enraizamento satisfatório após 1 ou 2 semanas e foram tranferidas após 14 a 20 dias para casa de vegetação.

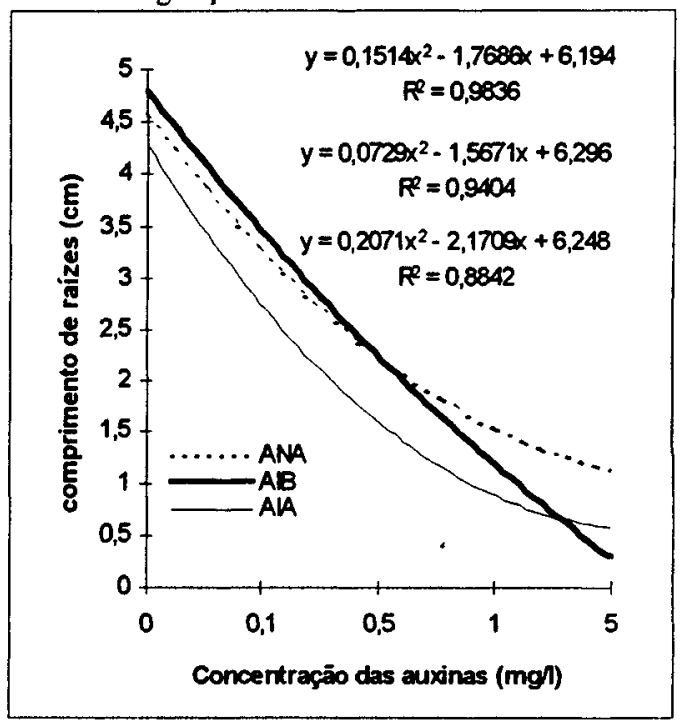

Figura 3. Número de raízes de bananeira, var. Maçã, cultivada em meios de cultura contendo AIA, AIB e ANA.

As plântulas, possuindo de $6-9 \mathrm{~cm}$ de altura, apresentaram boa resposta ao transplante, sendo que as perdas foram mínimas (3 - 5\%), em casa de vegetação, quando originadas de enraizamento realizado em meio sólido ou semi-sólido. As perdas, no entanto, elevaram-se para $20 \%$ quando as plântulas foram obtidas do cultivo em meio líquido, observando-se o ataque por microorganismos na região do colo das plantas. Uma provável explicação para este fato é que as plantas desenvolvidas em meio líquido sejam mais tenras e permitam mais facilmente $O$ ataque de microorganismos do solo.

CRONAURER \& KRIKORIAN (1984) após enraizarem plantas em meio semi-sólido, aclimataram as mesmas em recipientes com vermiculita e mantiveram sob nebulização por 10 a 14 dias, após o que puderam ser transferidas para 
TABELA 5. Número médio* de raizes em plântulas de bananeira "Maçã cultivadas in vitro, durante enraizamento através de diversas concentrações das auxinas AIA, AIB e ANA**

\begin{tabular}{cccc}
\hline $\begin{array}{c}\text { Concentração } \\
\left(\mathrm{mg} . \mathrm{H}^{-1}\right)\end{array}$ & AIA & AIB & ANA \\
\hline 0 & 3,75 ab A & 3,75 a A & 3,75 ab A \\
0,1 & 5,32 ab A & 5,08 a A & 6,70 a A \\
0,5 & 5,89 a A & 4,78 a A & 4,00 ab A \\
1,0 & 3,74 ab A & 3,42 a A & 3,87 ab A \\
5,0 & 3,05 b A & 3,38 a A & 3,12 b A \\
\hline \hline
\end{tabular}

* Médias seguidas de letras iguais minúsculas e maiúsculas, não diferem significativamente entre si, no sentido vertical e horizontal respectivamente. Avaliação pelo teste de Tukey - 5\% (CV.23,77\%)

** Avaliação após 14 dias da inoculação.

casa de vegetação. Para o presente trabalho foram utilizados mistura de solo, como substrato, composto de solo argiloso, esterco e areia, na proporção de 1:1:1 e os resultados foram favoráveis, e não foram necessários mais do que 4 - 5 dias sob nebulização, para a transferência para a casa de vegetação.

Recomenda-se, então, a passagem de brotos originados do cultivo em meio líquido para o meio sólıdo ou semi-sólido durante a fase de enraizamento de modo a garantir maior vigor para as plantas antes da aclimatação em casa de vegetação. Pode-se utilizar solo como substrato, e de preferência utilizar nebulização nos primeiros 4 - 5 dias de aclimatação, evitando-se porém que o solo fique encharcado.

\section{CONCLUSÕES}

1. O tipo de ápice caulinar em que se obteve o maior número de brotos foi o que sofreu a remoção das bainhas foliares.

2. Para a micropropagação da bananeira pode-se utilizar meio líquido sob agitação ou meio semi-sólido.

3. O tratamento de $5,0 \mathrm{mg} \cdot \mathrm{l}^{-1}$ de BAP, foi a menor concentração testada que induziu uma taxa de brotação satisfatória durante o cultivo de ápices caulinares de bananeira "Maçã".

4. Para a indução do enraizamento em plântulas de bananeira "Maçã" in vitro, recomendase a utilização de $0,1 \mathrm{mg} . \mathrm{l}^{-1}$ de AIB ou ANA, em meio semi-sólido, na ausência de citocinina. A utilização destes reguladores de crescimento nestas concentrações permite o enraizamento das plântulas de bananeira, as quais após aproximadamente 20 dias podem ser transferidas para a casa de vegetação.

\section{REFERÊNCIAS BIBLIOGRÁFICAS}

BANERJEE, N.; DE LANGHE, E. A tissue culture technique for rapid clonal propagation and storage under minimal growth conditions of Musa (banana and plantain) Plant Cell Reports, Heidelberg, v.4, p.351-354, 1985.

CRONAUER, S.S.; KRIKORIAN, A.D. Rapid multiplication of bananas and plantains by in vitro shoot tip culture. HortScience, Alexandria, v.19, p.234-235, 1984.

FAO PRODUCTION YEARBOOK - 1990, Rome, 44, 169 170, 1991.

GUPTA, P.F. Eradication of mosaic disease and rapid clonal multiplication of bananas and plantains through meristem tip culture. Plant Cell, Tissue and Organ Culture, Dordrecht v.6. p.33-39, 1986.

GODINHO, F.P. Efeito de doses de 6 - Benzilaminopurina na produção de mudas de bananeira (Musa sp) cultivar Prata, pelo método de propagação rápida in vivo. Lavras, 1991. 49p. Dissertação (Mestrado) - Escola Superior de Agricultura de Lavras.

LAMEIRA, O.A. Propagação in vitro da bananeira $M$ usa sp. através da cultura de ápice caulinar. Lavras, 1987. 39p. Dissertação (Mestrado) - Escola Superior de Agricultura de Lavras.

MOREL, G.; WETMORE, R.H. Fern callus tissue culture. American Journal of Botany, v.38, p.141-143, 1951.

MURASHIGE, T. Plant propagation through tissue cultures. Annual Review of Plant Physiology, Columbus, v.25, p.135-166, 1974.

MURASHIGE, T; SKOOG, F. A revised medium for rapid growth and bioassays with tobacco tissue cultures. Physiologia Plantarum, Palo Alto, v.15, p.473-497, 1962. 
NOVAK, F.J.; DONINI, B.; HERMELIN, T.; MICKE A. Potencial of banana and plantain improvement through in vitro mutation breeding. In: REUNION. CATIE, 8 , Turrialba, 1987. Memórlas ... Turrialba: CATIE, 1987. p.67-70.

NOVAK, F.J. In vitro mutation system for crop improvement. In: INTERNATIONAL ATOMIC ENERGY AGENCY. Plant mutation breeding for crop Improvement. Vienna, 1991. v.2, p.327-342.
SOUZA, F.V.D.; SHEPHERD, K.; SILVA, S. de O.; SOUZA, A.S. Instabilidade mitótica de plantas de bananeira (Musa spp.) oriundas de cultivo 'in vitro'. In: CONGRESSO BRASILEIRO DE FRIJTICULTURA, 13., Salvador, 1994. Anais ... Salvador: SBF, 1994. v.1, p.144.

VUYLSTEKE, D.; DE LANGHE, E. Feasibility of in vitro propagation of bananas and plantains. Tropical Agriculture, Trinidad, v.62, n.4, p.323-328, 1985.

Recebido para publicação em 21.06 .94

Aceito para publicação em 25.08 .95 